\title{
Una panorámica (problemática) del desarrollo en el Mundo Árabe
}

\author{
Jesús A. Núñez Villaverde'
}

Resumen: En términos de desarrollo, y a pesar de sus innegables potencialidades, el conjunto del mundo árabe ocupa posiciones muy atrasadas. Entre los factores que explican este inquietante panorama sobresale, por un lado, la responsabilidad acumulada por gobiernos occidentales que han apostado desde hace décadas por la estabilidad a toda costa, interesados fundamentalmente en garantizar su seguridad energética, aunque eso vaya en contra de sus propios valores y principios. Por otro, es el resultado de la voluntad de unos gobernantes locales que se distinguen principalmente por su autoritarismo, ineficacia y corrupción, centrados fundamentalmente en garantizar sus propios beneficios, de espaldas a unas poblaciones mayoritariamente jóvenes que aspiran a llevar una vida digna. La llamada "primavera árabe" es la más reciente señal del hartazgo que acumulan los más de 400 millones de árabes, sin que se vislumbre a corto plazo un cambio sustancial de tendencia.

Palabras clave: Desarrollo, Mundo Árabe, Primavera Árabe, Conflictos armados.

An overview (problematic) of development in the Arab World

Abstract: Seen as a whole, in spite of its undeniable potential, the Arab world lags far behind in terms of development. Among the factors that help explain this worrying panorama is, on the one hand, the shared responsibility of Western governments who
Une vue panoramique (problématique) du développement dans le monde arabe

Résumé: En termes de développement, et malgré son potentiel indéniable, le monde arabe dans son ensemble est très en retard. Parmi les facteurs qui expliquent ce panorama inquiétant, ily a, d'une part, la responsabilité accumulée des gouvernements occidentaux

' Codirector del Instituto de Estudios sobre Conflictos y Acción Humanitaria (IECAH). 
have been committed to stability at all costs for decades, interested primarily in guaranteeing their energy security, even if this meant violating their own values and principles. On the other hand, it is the result of the will of local rulers who are characterised primarily by their authoritarianism, inefficiency and corruption, focused primarily on seeking continued benefits for themselves, with their backs turned on a largely young population that aspires to lead a dignified life. With no substantial change in trend to be expected in the short term, the so-called 'Arab spring' is the most recent indicator of the weariness of the more than 400 million Arabs.

Key words: Development, Arab world, Arab spring, armed conflicts. qui, depuis des décennies, se sont engagés dans la stabilité à tout prix, intéressés avant tout à garantir leur sécurité énergétique, même si cela va à l'encontre de leurs propres valeurs et principes. D'autre part, elle est le résultat de la volonté de dirigeants locaux qui se distinguent principalement par leur autoritarisme, leur inefficacité et leur corruption, axés essentiellement sur la garantie de leurs propres avantages, le dos tourné à une population majoritairement jeune qui aspire à mener une vie digne. Ce que l'on appelle le "printemps arabe» est le signe le plus récent de la lassitude de plus de $\mathbf{4 0 0}$ millions d'Arabes, et aucun changement de tendance substantiel n'est en vue à court terme.

Mots clé: Développement, Monde Arabe, Printemps Arabe, Conflits armés.

Desde hace ya mucho tiempo los conceptos de desarrollo -en su más amplia acepción, abarcando el campo social, político y económico- y de mundo árabe -entendido como el conjunto de los 22 países miembros de la Liga Árabe- siguen rumbos divergentes. Así lo atestiguan los sucesivos informes que el Programa de las Naciones Unidas para el Desarrollo (PNUD) viene elaborando sin periodicidad fija desde 2004 para estos países, en los que se plasma una inquietante evolución negativa en todos los terrenos, más allá de ocasionales contrapuntos positivos ${ }^{2}$. Así lo señala en su última edición (de 2016) el "Informe sobre Desarrollo Humano para la Región Árabe 2016: La juventud y el futuro del desarrollo humano en una realidad cambiante" ${ }^{\prime \prime}$, apuntando especialmente al hecho de que un $30 \%$ de los 370 millones de personas que entonces vivían en esos países tenían entre 15 y 29 años y más del $60 \%$ de la población era menor de 30 años. Y aunque dicho informe arrancaba con un obligado tono positivo, haciendo referencia al hecho de que se trataba de la generación más preparada, activa y conectada con el

\footnotetext{
${ }^{2}$ Emiratos Árabes Unidos figuraba, en el puesto $31^{\circ}$, como el primer país árabe en el Índice de Desarrollo Humano de 2020, no muy lejos de España (en el puesto $25^{\circ}$ ).

3 https://www.arabstates.undp.org/content/rbas/en/home/library/huma_development/ arab-human-development-report-2016--youth-and-the-prospects-for-/
} 
resto del mundo en toda la historia contemporánea, el paso del tiempo tan solo ha servido para confirmar que hoy la situación es aún más problemática ${ }^{4}$.

Es evidente que la región tiene una enorme potencialidad de desarrollo, hasta el punto de que no cabe hablar de países pobres (ni siquiera en el caso de Yemen - Mauritania, que suelen aparecer como los más atrasados entre los árabes), sino de países empobrecidos. Su situación es el resultado de la gestión de sus considerables riquezas por parte de unos actores políticos y económicos locales, con un innegable apoyo de actores foráneos, interesados en su propio beneficio personal y en el mantenimiento a toda costa de un statu quo desequilibrado y negador de una vida digna para la inmensa mayoría de sus habitantes. Además de la ya mencionada juventud de su población posee ingentes recursos naturales, especialmente en el campo de los combustibles fósiles, y una diversidad de espacios entre el Magreb, Oriente Próximo y Oriente Medio en los que han florecido civilizaciones muy avanzadas en diferentes momentos de su historia. De hecho, conviene recordar que en apenas un siglo después del nacimiento del islam los árabes llegaron a conquistar un imperio que se extendía desde la Península lbérica hasta la India. Y durante mucho tiempo fueron ellos, en el orbe mediterráneo, los más avanzados en todos los ordenes de la vida social, política y económica, así como en las artes (incluyendo el militar), el pensamiento, la ciencia y las humanidades, contribuyendo de manera decisiva al avance de pueblos europeos entonces mucho más atrasados. De hecho, no es posible entender hoy la cultura europea si no se tienen en cuenta las enormes aportaciones de ese esplendoroso mundo árabo-musulmán que, sin embargo, hoy ocupa posiciones marginales en el escenario internacional.

Esa potencialidad, en el mejor de los casos, ha quedado hibernada bajo el peso sucesivo de un pasado históricamente marcado por la intervención foránea, primero con potencias europeas a la cabeza y posteriormente bajo el dictado estadounidense. Eso incluye no solo la colonización europea -que se inició en 1830, con Francia entrando en lo que hoy se denomina Argelia, y que no remató formalmente hasta 1971, con la independencia de manos británicas de países como Emiratos Árabes Unidos, Bahréin o Qatar-, sino también una descolonización que creó países artificiales, estructuralmente débiles y fragmentados al servicio de los intereses geopolíticos y geoeconómicos (seguridad energética) occidentales, y que se tradujo en el sostenido apoyo a gobernantes locales mucho más preocupados

${ }^{4}$ Dado que desde 2016 el PNUD no ha vuelto a elaborar un informe sobre desarrollo humano en el mundo árabe no se dispone de datos globales más actualizados. A lo largo del texto se recogen datos puntuales sobre diferentes países árabes extraídos de las fuentes que se detallan en cada caso. 
de mantenerse en el poder que de atender las necesidades y las demandas de sus propios súbditos (más que ciudadanos).

Las reglas de juego impuestas por las potencias occidentales, sobre todo durante la Guerra Fría, y el perfil escasamente democrático de los sucesivos gobernantes locales se combinaron para dar como resultado un statu quo que, básicamente, se conformó a partir de las decisiones occidentales de crear países artificiales, en los que tenían que convivir pueblos que no deseaban hacerlo y se separaba a los que tenían un destino común, lo que aseguraba una debilidad estructural que en no pocas ocasiones se ha traducido en un alto nivel de conflictividad interno. Asimismo, incluía la imposición y el apoyo a gobernantes subordinados a los dictados occidentales, permitiéndoles a cambio que pudieran disfrutar de un amplio margen de maniobra para beneficiarse personalmente de las riquezas nacionales, de espaldas a las necesidades y expectativas de sus propias poblaciones. A esa corresponsabilidad occidental, que incluye una alta dosis de incoherencia entre los valores que dice promover y los intereses que realmente defiende ${ }^{5}$, se añade, obviamente, la que recae en las espaldas de los distintos gobernantes locales, escasamente interesados en promover la democracia y el Estado de derecho. En consecuencia, la falta de voluntad de unos y otros para salirse de sus respectivas zonas de confort fue generando un panorama que, con diversas crisis, convulsiones y conflictos armados más o menos graves, finalmente desembocó en la movilización ciudadana que arrancó en diciembre de 2010 en Túnez, con la inmolación del joven Mohamed Bovazizi, y que pronto se extendió a otros países en el marco de lo que, mediáticamente, se ha dado a conocer como "la primavera árabe".

\section{I. “La primavera árabe” como síntoma de hartazgo}

Precisamente en esas movilizaciones confluyen todos los factores que permiten entender la frustración y desesperación de unas sociedades que finalmente se atrevieron a salir a las calles como víctimas principales de una crisis multifacética que mostraba la insostenibilidad de los modelos vigentes. Resulta útil repasar, aunque sea de manera esquemática, los diferentes ámbitos social, político, económico y de seguridad en los que ha fraguado esa manifestación de profundo malestar, no solo para conocer mejor lo sucedido sino también para identificar las asignaturas

\footnotetext{
${ }^{5}$ Sirva Arabia Saudí como ejemplo paradigmático, aunque en ningún caso único, de la considerable distancia que hay entre el discurso y la práctica política occidental.
} 
pendientes que quedan por superar para salir del túnel en el que está sumido el conjunto del mundo árabe.

Fueron, conviene recordarlo, unas movilizaciones con sobradas razones para la protesta, asentadas en unas causas estructurales (en buena medida comunes a toda la región) a las que solo faltaba la gota que terminara por colmar el vaso de la paciencia ciudadana. En contra de algunos estereotipos negativos muy asentados en la visión y el discurso occidental cabe decir que fueron, en primer lugar, movimientos espontáneos y populares. No existió un promotor ideológico o un liderazgo partidista o religioso que los pusiera en marcha, ni tampoco una mano negra extranjera que organizara desde la sombra una respuesta general contra los autócratas y dictadores de turno. En todo caso, a pesar de los múltiples intentos por identificar la razón última que explique lo ocurrido, ninguno de ellos resulta concluyente y solo cabe entender que lograron romper las clásicas barreras sectarias hasta convertirse en acciones transversales que mostraban el hartazgo, la frustración y la desesperación con la vida que les tocaba vivir. Lo que también cabe decir es que, a la luz del balance provisional que tenemos diez años después, en ninguno de los casos en los que se ha producido la caída del respectivo dictador se ha llegado a producir algo más que un cambio de caras $^{6}$; sin que eso signifique que algo así no pueda ocurrir en el futuro.

También es obvio que se sobredimensionó la importancia de las redes sociales, aunque solo sea por el hecho de que el bajo poder adquisitivo de amplias capas de la población les impide asumir los gastos que comporta la adquisición y uso de las tecnologías asociadas a dichas redes, sin olvidar el problema del analfabetismo que todavía sufren muchos de estos países. De mayor importancia cabe pensar que ha sido el impacto de un medio televisivo como Al Jazeera, que lleva ya más de veinte años haciendo llegar a la práctica totalidad de la población árabe (y más allá) una información crítica que no ofrece ninguno de los medios públicos de la zona. En cualquier caso, tanto unos como otros no fueron más que instrumentos que solo sirvieron para potenciar los anhelos de unas poblaciones globalmente desasistidas por parte de los poderes públicos y que aspiraban a dignificar su vida en un marco sociopolítico y económico más sensible a sus aspiraciones.

Fueron, igualmente, reclamaciones ciudadanas netamente políticas, a diferencia de las que caracterizaron las registradas en los años ochenta y noventa del pasado

${ }^{6}$ Con la notable excepción de lo ocurrido en Túnez, donde la caída del dictador tunecino Zine el Abidine ben Ali, el 14 de enero de 2011, ha llevado a un cambio de régimen que apunta a una transición democrática, todavía inconclusa a día de hoy. 
siglo, cuando lo que se demandaba era principalmente medidas socioeconómicas que aliviaran el impacto que supuso la aplicación de los programas de ajuste estructural y de estabilización. Sin negar de ningún modo la relevancia de un sustrato socioeconómico claramente negativo para la inmensa mayoría de la población, en esta ocasión las movilizaciones reclamaron ya desde el principio la caída de los gobernantes y la aplicación de profundas reformas en los modelos políticos imperantes. Unos gobernantes reacios a rendir cuentas de sus actos y percibidos como corruptos, ineficientes, fracasados y sin voluntad alguna para modificar sus pautas de comportamiento.

También fueron movimientos pacíficos. De hecho, la violencia fue, una vez más, la opción recurrente de unos gobiernos acostumbrados a reprimir por la fuerza cualquier tipo de contestación a su poder. En esa línea, resulta asombroso constatar la pérdida del miedo que durante demasiado tiempo había mantenido paralizada a buena parte de la ciudadanía, temerosa de ser castigada brutalmente por unos gobernantes con un amplio historial de violaciones de los derechos humanos. Esto hizo que, a pesar de la violencia ejercida por el poder, la población siguiera atreviéndose a hacer visible su protesta en las calles, en una clara muestra de su voluntad de no cejar en su empeño por el cambio.

No cabe ninguna duda de que fueron, asimismo, protagonizadas por los jóvenes. $Y$, sin restarle un ápice de importancia a esta variable, interesa recordar que la entonces denominada "bomba demográfica" en el mundo árabe se produjo a finales de los años ochenta del pasado siglo. Eso significa que ya desde entonces quedó clara la falta de voluntad de los responsables políticos para dar satisfacción a las crecientes necesidades de educación, sanidad, vivienda y trabajo de una población mayoritariamente joven. Hoy, los jóvenes son el colectivo más numeroso en la práctica totalidad de los países del área y son ellos, por tanto, los que tienen más oscuro su presente y su futuro. No puede sorprender, por tanto, que no confíen en unos gobernantes anclados en sus puestos y en una clase política cooptada por el poder o desligada de la realidad de la calle. También resulta natural que hayan sido ellos los que con mayor entusiasmo se hayan atrevido a cuestionar el statu quo vigente, intentando convertirse en protagonistas de su propio destino. Esto no quiere decir, sin embargo, que el resto de los colectivos sociales no hayan movilizado igualmente a favor del cambio.

Por último, han supuesto una magnífica lección que ayuda a derribar estereotipos muy asentados. Frente a una visión muy consolidada en Occidente que tiende a considerar a las sociedades árabes como pasivas frente al poder, no preparadas para la democracia y esencialmente violentas, se impone cada vez con mayor 
claridad que lo que estamos viviendo es un ejemplo de activismo ciudadano que aspira exactamente a lo mismo que reclamamos quienes habitamos las sociedades desarrolladas y democráticas. Si hubiera que resumir sus demandas basta con recordar que pretenden comer tres veces al día, expresar sus ideas sin temor a la represión y moverse con libertad en el marco de un Estado de derecho. En esa misma línea, cabe considerar que esta "primavera" supone una derrota sin paliativos de los movimientos salafistas y del yihadismo de Al Qaeda o Dáesh. Estos grupos se ven a sí mismos como una punta de lanza del descontento de la población y llevan mucho tiempo queriendo derribar a muchos de los gobiernos árabes que consideran ilegítimos. Sin embargo, quienes se han movilizado contra sus propios gobernantes no lo han hecho al grito de "Alá es grande" o "el islam es la solución", siguiendo a los iluminados líderes yihadistas, sino que, dándoles la espalda, han reclamado insistentemente "libertad, dignidad y trabajo".

Además de ese conjunto de características de lo que unos han optado por llamar primavera y otros despertar, revueltas o revoluciones, la imagen de la región como una bomba a punto de explosionar se completa con unos datos que dejaban poco espacio a la esperanza. En primer lugar, el ya citado informe del PNUD recordaba que, medido por el Índice de Desarrollo Humano (IDH), aunque todos los países árabes incrementaron sus avances en el periodo 1980-2010 -con ganancias notables en educación y salud y un menor avance en los niveles de ingreso-, el efecto combinado de la crisis económica de 2008 y la inestabilidad política generada desde el arranque de la "primavera árabe" ya supuso en el periodo 2010-2014 una caída global en el IDH de más del $50 \%$ en relación con la década anterior. Una derivada inmediata de esa caída ha sido el aumento de las que ya eran entonces notorias brechas de desigualdad. Así, el IDH en la región, ajustado por esa variable, cayó 24,9 puntos, claramente por encima de los 22,9 de promedio mundial. Por su parte, el componente de educación todavía registraba ya entonces la mayor brecha, superando los 38 puntos.

Datos más recientes ${ }^{7}$, referidos a encuestas realizadas a ciudadanos de doce países árabes $^{8}$ en 2019 , muestran que el $28,5 \%$ no podían conseguir comida suficiente para alimentarse, mientras que únicamente un $6,5 \%$ podía no solo cubrir sus necesidades básicas sino también comprar regularmente ropa y muebles e incluso

\footnotetext{
7 Amaney Jamal/Paola Pagliani/Ellen Hsu (2020): Citizenship 360 in the Arab Region. Perceptions on Sustainable Development across Countries, Income, and Gender. Arab Human Development Report RESEARCHPAPER https://arab-hdr.org/wp-content/uploads/2021/03/Final-Citizenship-360-in-theArab-Region.pdf

${ }^{8}$ Argelia, Egipto, Irak, Jordania, Líbano, Libia, Marruecos, Palestina, Somalia, Siria, Túnez y Yemen.
} 
ahorrar. Por su parte el informe del Banco Mundial publicado en 2018, Poverty and Shared Prosperity: Piecing Together the Poverty Puzzle9, confirmaba que la región $\mathrm{MENA}^{10}$ era la única del planeta en la que la pobreza extrema había aumentado en el periodo $2011-2015$, pasando del 2,7\% al 5\% ${ }^{11}$. La información más reciente sobre esta misma variable, siguiendo el mismo informe del Banco Mundial de 2020 y a la espera del efecto adicional que ya está provocando la pandemia de la COVID-19, confirma esa negativa evolución de la pobreza extrema hasta alcanzar el 7,2\% de la población.

Esa es una de las claves principales para explicar la frustración y el hartazgo de unas poblaciones que no solo no ven satisfechas sus necesidades más básicas, sino que son tratadas por sus gobiernos como sujetos pasivos incapaces de asumir su propio desarrollo. En paralelo, se han deteriorado progresivamente los sistemas de salud y educación, ha empeorado el problema de la vivienda y se ha hecho cada más difícil el acceso al mercado laboral. De hecho, la incapacidad de traducir los ya mencionados avances en el plano educativo en empleos dignos para una población eminentemente joven, al mismo ritmo del crecimiento demográfico, no ha hecho más que incrementar la tensión social y políica. Según el ya citado informe del PNUD, en 2014 el desempleo juvenil en los países árabes $(29,73 \%)$ era más del doble del promedio mundial (13,99\%). Y ya entonces se advertía que, sin acciones drásticas e inmediatas, las economías árabes no podrían generar los 60 millones de nuevos puestos de trabajo que se requerirían para absorber a la nueva población en edad laboral en 2020 y estabilizar al menos el desempleo juvenil. Todo ello, mientras a esas alturas la válvula de la emigración (fundamentalmente hacia el Viejo Continente) ya se había prácticamente cerrado, convirtiendo a la Unión Europea en una fortaleza cada vez más empeñada en una política migratoria esencialmente policial y restrictiva. La consecuencia obvia de todo ello fue (y sigue siendo) el aumento de la presión en una olla que, finalmente, explotó en diciembre de 2010 en Sidi Bouzid (Túnez) y que, en sucesivas oleadas, nos lleva hasta una actualidad muy preocupante.

A eso se suma, con los datos acumulados tras una década de movilizaciones ciudadanas que han provocado la caída de seis dictadores -Túnez, Egipto, Libia y Yemen, en 2011, seguidos de Argelia y Sudán, en 2019-, un panorama político

${ }_{9}$ https://www.worldbank.org/en/publication/poverty-and-shared-prosperity-2018

10 Norte de África y Oriente Medio (Middle East and North Africa).

${ }^{11}$ Lo que suponía un total de 18,6 millones de personas viviendo con menos de 1,90 dólares diarios. 
muy cuestionado. Al margen de su carácter formal, como monarquías o repúblicas, es inmediato concluir que ninguno de los sistemas políticos del mundo árabe es plenamente democrático. E incluso el estallido de la pandemia de la COVID-19 ha servido para recortar aún más el limitado marco de derechos y libertades de unos sistemas políticos manifiestamente mejorables en todos los aspectos. En esencia, y siguiendo los datos que aportaba Freedom House en su índice anual sobre democracia en el mundo ${ }^{12}$, en 2020 tan solo Sudán ha mejorado ligeramente su posición, mientras únicamente Marruecos, Mauritania y Kuwait aparecen como sistemas "parcialmente libres", en tanto que Jordania y Egipto son los dos países que más han seguido cayendo en sus niveles de libertad política.

Y no es, desgraciadamente, mejor el balance regional cuando se hace referencia a los niveles de conflictividad y violencia. Aunque solo es el hogar del $5 \%$ de la población mundial, la región árabe ha sufrido el $17 \%$ de todos los conflictos registrados en el planeta entre 1948 y 2014. En la actualidad, tal como recoge la Escuela de Cultura de Paz en su informe Alerta 2021 ${ }^{13}$, del total de 34 conflictos armados activos el pasado año, 9 se localizaban en el mundo árabe (Egipto (Sinaí), Irak, Israel-Palestina, Libia, Somalia, Sudán, Sudán del Sur, Siria y Yemen). Asimismo, de los 16 contextos de tensión de máxima intensidad recogidos en sus páginas, los países árabes aparecen nuevamente mencionados en relación con los que se localizan en Marruecos-Sáhara Occidental, Irán, Israel-Palestina, Egipto, Irak e Israel-Siria-Líbano. Un panorama altamente desestabilizador al que se añade la violencia provocada por diversos grupos yihadistas, con Dáesh y Al Qaeda (más sus ramificaciones locales) a la cabeza, más la ejercida por los sistemas represivos de los distintos gobiernos en su intento de acallar las críticas y las protestas de sus propias poblaciones.

Como es bien sabido ese alto nivel de violencia e inestabilidad no solo tiene un alto coste en vidas humanas, sino que también afecta muy negativamente al tejido social y económico de la región, destruyendo recursos, capital y fuentes de trabajo. Sirva de ejemplo lo que ocurre en Siria desde el arranque del conflicto a principios de 2011, con más de medio millón de muertos, 6,7 millones de desplazados internos y casi 5,6 millones de refugiados (de un total estimado en 23 millones habitantes), mientras el país ha sido prácticamente destruido por los distintos actores combatientes. El listado de situaciones trágicas pueden extenderse a tantos

\footnotetext{
12 https://freedomhouse.org/sites/default/files/2021-02/FIW2021_World_02252021_FINAL-webupload.pdf

${ }^{13}$ https://escolapau.uab.cat/img/programas/alerta/alerta/21/alerta21.pdf
} 
otros escenarios como el que afecta a los palestinos, con más de 5,6 millones de refugiados y una constante política de hechos consumados por parte de Israel que busca el dominio total del territorio de la Palestina histórica contando con su abrumadora superioridad de fuerzas, el inequívoco respaldo de Washington, la pasividad de la Unión Europea y el bien visible ostracismo del resto de los países árabes que ya no ocultan sus deseos de normalizar relaciones con la potencia ocupante. Mientras tanto, Yemen se ha convertido en la mayor crisis humanitaria del planeta, según la $\mathrm{ONU}$, y sigue sumido en un conflicto para el que no se adivina solución a corto plazo. Y lo mismo cabe decir de la tragedia que sufre la población libia, sin olvidar la caída en el pozo que se registra en Líbano e Irak o el abandono en el que han quedado los saharavis ante un Marruecos que se siente crecientemente fortalecido ${ }^{14}$.

Sin abandonar ese campo, y a pesar de los últimos reveses sufridos por Dáesh con la pérdida del pseudocalifato que había proclamado en junio de 2014 en parte de Siria y de Irak, es obligado volver a hacer referencia al terrorismo yihadista. En ningún caso cabe considerar que esa amenaza haya desaparecido, sino que, por el contrario, sigue desgraciadamente muy presente. Así ocurre tanto en el Magreb, con Al Qaeda del Magreb Islámico, como en Oriente Próximo y Oriente Medio, llegando hasta Afganistán y el subcontinente indio, sin olvidar a varios países del Sahel africano, donde su presencia incluso se hace aún más intensa. Como acaba de demostrar nuevamente el fracaso cosechado en Afganistán, donde se está completando la retirada de las tropas extranjeras después de veinte años y donde los talibanes parecen cada vez más envalentonados, el protagonismo de los medios militares no ha resultado eficaz para acabar con esa lacra violenta, y menos aún si no se modifican sustancialmente las causas estructurales que sirven de caldo de cultivo para su florecimiento.

En conclusión, el panorama regional mostraba hace una década, y sigue mostrando en la actualidad, un conjunto de factores altamente preocupantes, tanto desde el punto de vista del desarrollo como desde el de la seguridad. En pocos sitios es más obvia la necesidad de conjugar en la práctica el planteamiento que ya defendía en marzo de 2005 el entonces secretario general de la ONU, Kofi Annan. En su informe "Un concepto más amplio de libertad: desarrollo, seguridady derechos humanos para todos ${ }^{\prime 15}$, insistía en la idea de que esos son los tres pilares

\footnotetext{
${ }^{14} \mathrm{Y}$ más aún desde que, en diciembre del pasado año, Donald Trump decidió reconocer el Sahara ocupado como territorio marroquí.

${ }^{15}$ https://www.un.org/spanish/largerfreedom/contents.htm
} 
centrales de un nuevo orden internacional. Un orden que entienda que no puede haber desarrollo sin seguridad, no puede haber seguridad sin desarrollo, y no puede haber ni uno ni otro si no hay un pleno respeto de los derechos humanos. Esa es, probablemente, la principal asignatura pendiente que hoy en día tenemos no solo en el mundo árabe sino en referencia a la totalidad de los seres humanos que habitamos este pequeño planeta.

\section{Mirando hacia adelante: agendas enfrentadas}

Por eso, mirando hacia adelante, la primera consideración a retener es la de que el camino no está cerrado ${ }^{16}$. Es posible, sin duda, encontrar una salida al oscuro callejón en el que estas sociedades llevan tanto tiempo metidas. Pero para ello es preciso contar con gobernantes legitimados a los ojos de sus propias poblaciones y tomar urgentemente decisiones que mejoren sustancialmente el bienestar, la productividad, la autodeterminación y el empoderamiento ciudadano, empezando por los jóvenes y, particularmente, las mujeres. Unas mujeres que, como recuerda nuevamente el ya mencionado informe del PNUD de 2016, no logran alcanzar y utilizar su pleno potencial como resultado de la profunda discriminación derivada de la persistencia de unos patrones culturales y unas tradiciones impuestas por el sistema educativo, las estructuras religiosas, los medios de comunicación y las tradicionales relaciones familiares, así como una diversidad de obstáculos legales.

Para encarar esa senda con determinación es necesario que se produzca una confluencia de voluntades entre todos los actores externos conectados con la región, los actores políticos y económicos locales -que mantienen en sus manos las principales palancas de poder- y los actores de la sociedad civil, con toda su diversidad. Y ahí es donde está el principal problema porque, al menos hasta ahora, no parece que unos y otros vayan en la misma dirección.

La sociedad civil es, con diferencia, el actor más decididamente movilizado a favor del cambio. Pero de inmediato queda de manifiesto que es el peor equipado de cuantos se mueven hoy en el escenario árabe. Y esto es así como consecuencia directa de una larga tradición de represión por parte de unos regímenes políticos interesados en maniatar a sus poblaciones, con una estrategia en la que se han

\footnotetext{
16 Un balance detallado y actualizado de lo ocurrido durante la pasada década y de posibles vías de desarrollo futuro se recoge en Álvarez-Ossorio, Ignacio y otros (2021): Movilizaciones populares tras las Primaveras Árabes (2011-2021), La Catarata, Madrid.
} 
ido combinando la cooptación de líderes emergentes, el clientelismo paternalista para comprar la paz social y la represión (encarcelamiento, muerte o exilio) de los opositores. Aunque en algunos casos ha habido sistemas formalmente multipartidistas desde hace años, nadie puede llamarse a engaño respecto a su escasísima representatividad, lo que ha derivado en un abrumador desinterés ciudadano por una clase política absolutamente desprestigiada.

Los distintos regímenes políticos se han encargado de bloquear la emergencia de una sociedad civil fuerte, que no ha tenido más remedio, en consecuencia, que moverse en los resquicios que dejan unos sistemas cerrados a los miembros de unas elites desconectadas completamente de las expectativas y necesidades de su población. En estas condiciones, y más allá del visible orgullo y autoestima de una población que se siente capaz de movilizarse contra sus gobernantes, hay que recordar que los nuevos actores políticos (con la excepción obvia de los grupos islamistas) no disponen de estructuras sólidas para adentrarse en la nueva etapa que se vaya abriendo tras la desaparición de sus odiados gobernantes. Por un lado, no tienen una maquinaria partidista bien engrasada y tampoco les sirven las de los partidos existentes; pero, por otro, son absolutamente neófitos en la gestión de los asuntos públicos. Corren el riesgo, por tanto, de agotarse en la mera movilización permanente o de ser manipulados por otros más diestros en los asuntos de poder, como ya ha ocurrido en muchos de los procesos electorales que se han celebrado tras la caída del gobernante de turno.

Podemos hablar sin rodeos de que se está produciendo una contrarrevoluciónliderada por Arabia Saudí y Emiratos Árabes Unidos, pero a la que también se apuntan los gobernantes de Egipto, Siria y muchos otros países- que suma fuerzas para frenar cualquier deriva que pueda desestabilizar sus posiciones de dominio. Gobernantes que no tienen reparos en reprimir violentamente a sus críticos y disidentes, violar sistemáticamente sus derechos básicos y censurar los medios de comunicación y las redes sociales; todo ello mientras las potencias occidentales miran hacia otro lado o les muestran su respaldo ${ }^{17}$.

Por su parte, el islamismo político resurge con una fuerza imparable. Aprovechando el peso que la identidad islámica tiene en la práctica totalidad de la población y los errores de cálculo de unos gobernantes que consideraban que el islam no era

\footnotetext{
${ }_{17}$ Pocos ejemplos de ceguera política y de incoherencia hay tan evidente como el apoyo occidental al golpe de Estado liderado en julio de 2013 por Abdelfatah al Sisi, en Egipto, abortando un proceso político que por primera vez había colocado en la presidencia a un civil y líder de los Hermanos Musulmanes, elegido democráticamente por los votantes.
} 
un rival político (sino más bien una vía para evitar derivas antisistema, al menos hasta principios de la última década del pasado siglo), el islamismo político ha resurgido de sus cenizas para convertirse en la opción políitica más atractiva. Para ello no solo han logrado un alto grado de disciplina y organización interna, sino que se han ganado los favores de amplios colectivos de población, tanto con su denuncia y critica de unos gobiernos crecientemente deslegitimados, como con su constante atención a los más desfavorecidos.

Como conclusión, estos grupos son hoy la punta de lanza de una nueva oleada de islamismo político que, a buen seguro, será muy pronto imitada por otras sociedades de la región en cuanto se puedan celebrar elecciones libres (Libia, Siria y Yemen entre ellos). Además, otros como Hamas y Hezbolá están en condiciones de tener un papel principal en sus respectivos feudos palestino y libanés. Seguramente el islamismo político -que no cabe confundir en ningún caso con el terrorismo yihadista- no sea la solución a los problemas que hoy sufren esas sociedades; pero de ningún modo puede negarse la realidad que los convierte en protagonistas principales de esta próxima etapa. En unos casos -como el papel de las mujeres en la vida pública- las dudas son inmediatas y en otros-como la política económica o de seguridad- las indefiniciones son mucho mayores que las certezas. Por tanto, no es posible llegar a ninguna conclusión definitiva sobre el efecto que pueda tener su irrupción en la primera línea política.

En cuanto a los países occidentales todo parece indicar que, más allá de las palabras, siguen en gran medida aferrados a una visión obsesionada con el mantenimiento del vigente statu quo. Aunque en el plano discursivo asomen algunos elementos de cambio, la realidad muestra como las consideraciones geopolíticas y geoeconómicas siguen pesando sobremanera en la actuación de las potencias occidentales. La dependencia energética es, por sí sola, un elemento central para entender el temor occidental ante las convulsiones de una región que alberga al menos las $2 / 3$ partes de las reservas mundiales de petróleo y no menos del $50 \%$ de las de gas. Es eso lo que explica nuevamente la habitual práctica del doble rasero- que apostaba militarmente por la caída de Gadafi, pero que prefiere olvidar la brutal represión que Bashar el Asad ejerce contra su pueblo o aceptar sin crítica alguna la intervención militar de Arabia Saudí en territorio de Bahréin y de Yemen. Poco puede sorprender, como consecuencia de la experiencia acumulada desde hace ya más de un siglo, que en paralelo siga aumentando el sentimiento antioccidental en amplias capas de la opinión pública árabe.

Tanto Estados Unidos como los países de la Unión Europea están encontrando enormes dificultades para moverse en este contexto cambiante. Por un lado, por- 
que arrastran un balance muy negativo como corresponsables en la configuración de un orden regional que ha apostado por la estabilidad impuesta por la fuerza, apostando por socios impresentables desde los esquemas que decimos defender. Por otro lado, porque el comportamiento actual también dista de ser el adecuado. En lugar de desmarcarse abiertamente de estos gobernantes y ponerse al lado de quienes demandan un cambio estructural, es muy notorio el empleo de una doble vara de medida y el temor por quedarse en el lado equivocado cuando se resuelvan de algún modo las crisis actuales en estos países.

En definitiva, a la espera de que el tiempo vaya confirmando o arrinconando hipótesis y reforzando o debilitando a unos actores frente a otros, la región sigue lastrada en términos de desarrollo. No solo eso, sino que está inmersa en una carrera en la que, por un lado, apuntan posibilidades de cambio y mejora- impulsadas por actores por capacidades muy limitadas-, mientras que por el otro se mueven otros más poderosos, empeñados en optar por el más de lo mismo. Es cierto que los segundos no parecen entender que ya no hay forma de controlar mansamente a unas poblaciones que se han liberado del miedo y que aspiran a una vida mejor. Pero también lo es que los primeros, por sí solos, parecen condenados a chocar una y otra vez con paredes que superan sus capacidades. Sin que eso vaya a ser el factor determinante, la opción que finalmente tomen las potencias occidentales (antes de que China cobre ventaja) puede acabar siendo un factor relevante en la ecuación. Veremos. 